Original

Article

\title{
Gender Differences in Predictors and Long-Term Mortality of New-Onset Postoperative Atrial Fibrillation Following Isolated Aortic Valve Replacement Surgery
}

\author{
Mariana Fragão-Marques, MD, ${ }^{1,2}$ Jennifer Mancio, MD PhD,${ }^{1}$ João Oliveira, BSc, ${ }^{1}$ \\ Inês Falcão-Pires, $\mathrm{PhD},{ }^{1}$ and Adelino Leite-Moreira, $\mathrm{MD} \mathrm{PhD}^{1,2}$
}

\begin{abstract}
Purpose: Postoperative atrial fibrillation (POAF) after coronary artery bypass grafting (CABG) has been associated with increased risk of death in women but not in men. We aimed to explore predictors and long-term mortality in POAF following isolated aortic valve replacement (AVR) surgery in men and women.

Methods: This study included 379 severe aortic stenosis patients with no prior atrial fibrillation (AF) who underwent isolated AVR surgery. We used multiple logistic regression to investigate independent gender-specific predictors of new-onset POAF, and we performed Kaplan-Meier (KM) to determine the impact of POAF in long-term mortality according to gender.

Results: Advanced age and coronary artery disease prevalence were higher among POAF patients in both genders. On multiple analysis, increased postoperative peak lactate was independently associated with POAF in men, while lower mean aortic valve gradient was associated with POAF in women. Area under the curve (AUC) for the model was 0.77 [0.68-0.86] and 0.69 [0.60-0.78] for men and women, respectively. At 4-year follow-up, POAF was linked to increased risk of death in men but not in women.

Conclusion: In severe aortic stenosis, factors associated with POAF and its impact on mortality differed between genders, with an increased risk of death observed only in men.
\end{abstract}

Keywords: postoperative atrial fibrillation, aortic stenosis, risk factors, mortality, gender

${ }^{1}$ Department of Surgery and Physiology, Faculty of Medicine, University of Porto, Portugal

${ }^{2}$ São João University Hospital Center, Porto, Portugal

Received: November 27, 2019; Accepted: January 28, 2020

Corresponding author: Mariana Fragão-Marques, MD. Department of Surgery and Physiology, Faculty of Medicine, University of Porto, 4200 Porto, Portugal

Email: marianaifrm@gmail.com

This work is licensed under a Creative Commons Attribution-NonCommercialNoDerivatives International License.

(C)2020 The Editorial Committee of Annals of Thoracic and Cardiovascular Surgery

\section{Introduction}

Atrial fibrillation (AF) remains the most common complication after cardiac surgery, ${ }^{1)}$ which occurs more frequently in valvular than in coronary artery bypass grafting (CABG) surgery (38-64\% versus $17-33 \%){ }^{2-4)}$ Aortic stenosis is the most common valvular disease, ${ }^{2)}$ with increasing incidence due to aging demographics, particularly in women, that negatively affects the quality of life and survival.,5) Aortic valve replacement (AVR) surgery still remains the gold standard for severe symptomatic aortic valve stenosis, improving quality 
of life and overall survival., ${ }^{4,5)}$ Although several studies have explored the influence of gender in outcomes after cardiac surgery, most of these focused on CABG. Female gender has been reported as a risk factor in several cardiovascular diseases, namely with regard to mortality and postoperative complications, including increased hospital stay and in-hospital morbidity, such as postoperative atrial fibrillation (POAF). ${ }^{78}$ Little is known about gender-specific POAF independent predictors in aortic stenosis. Stratifying POAF risk according to gender could improve POAF prediction and tailor patient management. In this study, we aimed to explore whether POAF-related factors differ by gender and how POAF influences long-term mortality in both genders.

\section{Materials and Methods}

This study aimed to compare the risk factors for POAF for each gender; study the survival between POAF and postoperative sinus rhythm (POSR) in men and women.

\section{Study population}

Between January 2014 and December 2015, 1353 consecutive patients who were submitted to isolated AVR surgery were retrospectively analyzed. We excluded (1) reoperations and emergent cases and patients with other concomitant procedures, including $\mathrm{CABG}$, aorta or other valvular surgery; (2) documented history of endocarditis or previous permanent or paroxysmal AF; (3) severe aortic regurgitation and more than mild mitral or tricuspid valve disease. Ultimately, we included 379 patients with aortic stenosis and a balanced distribution between genders (194 (51.2\%) were women). This study was approved by the institution's ethics committee and data confidentiality was assured.

\section{Data collection}

Patients had an echocardiography up to 6 months prior to surgery; all indexed measurements are normalized to body surface area (BSA). Smoking was considered when patients reported being active smokers or past smokers within less than a year. Median follow-up time for this cohort was 38 months. All gathered data were introduced in a coded database. Prolonged length of stay (LOS) was defined as the time of hospitalization above the 75th percentile. Hemodynamic instability was considered when inotropic support was needed during the postoperative period. Reported in-hospital outcomes included in-hospital mortality, stroke, myocardial infarction, cardiac arrest, atrioventricular block, and infection.

Primary outcomes were long-term all-cause mortality and occurrence of new-onset AF during the postoperative period. POAF was monitored by telemetry during the first $48 \mathrm{~h}$ post-surgery and afterwards by electrocardiogram (ECG) if an arrhythmic pulse was detected. It was assessed through telemetry and ECG recordings and doctors and nurses records. POAF was defined both electro-physiologically and clinically as recommended by the American Association for Thoracic Surgery: ECG recordings which demonstrate characteristics AF findings for at least 30 seconds or for the entirety of the ECG if shorter than 30 seconds; clinically significant $\mathrm{AF}$ which requires treatment with rate or rhythm control agents, anticoagulants or increases hospital stay. ${ }^{9)}$

\section{Statistical analysis}

IBM SPSS Statistics version 25 was used for all statistical analysis. Categorical variables were presented as percentages and continuous variables as mean and standard deviation. Categorical variables were analyzed using chi-squared test or Fisher's exact test when appropriate and continuous variables were analyzed with t-test for independent samples. Multiple analysis was performed using a logistic regression model through a stepwise approach to fit the model and find independent POAF predictors in both genders; included variables were tested for collinearity and sample size was considered when defining the final multivariate model. The area under the curve (AUC) of a receiving operating characteristic (ROC) curve was used to test the predictive value of the model in each gender group. Survival analysis was conducted using the Kaplan-Meyer (KM) method; Log-Rank and Breslow tests, and Cox Regression were used to evaluate risk factors affecting survival.

\section{Results}

\section{Patient demographics}

Patient characteristics are listed in Table 1. Women were significantly older than men, with a mean age at operation of $72.8( \pm 9.7)$ and $68.5( \pm 10.5)$, respectively $(\mathrm{p}<0.001)$. Symptoms at presentation were similar between genders, including angina, syncope, and New York Heart Association (NYHA) functional class. The percentage of smoking men was much higher when compared to women, with $63 \%$ vs $7 \%(\mathrm{p}<0.001)$ of patients being active smokers or ex-smokers within less than a year. 
Table 1 Patient characteristics

\begin{tabular}{|c|c|c|c|}
\hline & Female & Male & $\mathrm{p}$ value \\
\hline Age (years, mean [SD]) & $72.8(9.7)$ & $68.5(10.5)$ & $<0.001$ \\
\hline Angina (n [\%]) & $49(25.3)$ & $52(28.1)$ & 0.530 \\
\hline Syncope (n [\%]) & $24(12.4)$ & $26(14.1)$ & 0.642 \\
\hline NYHA > I (n [\%]) & $104(53.6)$ & $89(46.1)$ & 0.284 \\
\hline Smoking (n [\%]) & $7(3.6)$ & $63(34.1)$ & $<\mathbf{0 . 0 0 1}$ \\
\hline Diabetes (n [\%]) & $72(37.1)$ & $57(30.8)$ & 0.196 \\
\hline Hypertension (n [\%]) & $141(72.7)$ & $133(71.9)$ & 0.864 \\
\hline Dyslipidemia (n [\%]) & $137(70.6)$ & $124(67)$ & 0.450 \\
\hline Pulmonary hypertension (n [\%]) & $64(75.3)$ & $37(72.5)$ & 0.723 \\
\hline Chronic lung disease (n [\%]) & $30(17.1)$ & $40(23.5)$ & 0.140 \\
\hline Coronary artery disease (n [\%]) & $16(9.0)$ & $26(14.9)$ & 0.089 \\
\hline Cerebrovascular disease (n $[\%])$ & $25(13)$ & $16(8.6)$ & 0.173 \\
\hline Neoplasia (n [\%]) & $18(9.3)$ & $11(5.9)$ & 0.217 \\
\hline Statins (n $[\%])$ & $124(71.3)$ & $107(67.7)$ & 0.483 \\
\hline Beta-blockers (n [\%]) & $63(36.2)$ & $51(32.3)$ & 0.452 \\
\hline ACEI/ARB (n [\%]) & $122(70.1)$ & $103(65.2)$ & 0.338 \\
\hline Diuretics (n [\%]) & $112(64.4)$ & $88(55.7)$ & 0.107 \\
\hline \multicolumn{4}{|l|}{ Ejection fraction } \\
\hline Preserved (n [\%]) & $158(88.8)$ & $141(87.6)$ & 0.601 \\
\hline Mildly reduced (n [\%]) & $8(4.5)$ & $11(6.8)$ & \\
\hline Reduced (n [\%]) & $12(6.7)$ & $9(5.6)$ & \\
\hline Indexed left atrium diameter (mm/BMI, mean [SD]) & $720.2(96.4)$ & $679.6(84.4)$ & $<0.001$ \\
\hline Indexed left ventricle diameter (mm/BMI, mean $[\mathrm{SD}])$ & $818.8(157.7)$ & $796.2(133.3)$ & 0.180 \\
\hline $\begin{array}{l}\text { Indexed interventricular septum thickness (mm/BMI, } \\
\text { mean }[\mathrm{SD}] \text { ) }\end{array}$ & $225.7(42.0)$ & $207.5(32.8)$ & $<0.001$ \\
\hline PSAP $(\mathrm{mmHg}$, mean $[\mathrm{SD}])$ & $37.4(11.4)$ & $35.8(8.7)$ & 0.376 \\
\hline Maximum aortic gradient $(\mathrm{mmHg}$, mean $[\mathrm{SD}])$ & $85.3(20.0)$ & $80.5(18.7)$ & $\mathbf{0 . 0 2 7}$ \\
\hline Mean aortic gradient (mmHg, mean [SD]) & $54.0(14.4)$ & $50.6(12.9)$ & 0.018 \\
\hline Aortic valve area $\left(\mathrm{cm}^{2}\right.$, mean $\left.[\mathrm{SD}]\right)$ & $0.71(0.18)$ & $0.79(0.19)$ & $<\mathbf{0 . 0 0 1}$ \\
\hline Mitral valve (n [\%]) & 87 (50.6) & 75 (46.9) & 0.500 \\
\hline Tricuspid valve (n [\%]) & $46(31.7)$ & $37(27.4)$ & 0.429 \\
\hline
\end{tabular}

ACEI/ARB: angiotensin converting enzyme inhibitor/angiotensin receptor blocker; NYHA: New York Heart Association Functional Classification; PSAP: pulmonary systolic arterial pressure

Other cardiovascular risk factors were equally distributed among genders (diabetes, hypertension, and dyslipidemia). Pulmonary hypertension, chronic lung disease, cerebrovascular disease, and presence of neoplasia did not differ between men and women. Although surgical coronary artery disease was an exclusion criterion, some patients had non-surgical coronary artery disease, which was similar between groups (9\% vs $14.9 \%$ in women and men, respectively, $\mathrm{p}=0.089$ ). Most patients had preserved ejection fraction $(88.8 \%$ vs $87.6 \%, \mathrm{p}=0.601)$ and mild mitral and tricuspid valve disease were equally distributed. Female patients had more severe disease at presentation, with increased indexed left atrium diameter and septum thickness, as well as maximum and mean aortic valve gradient; the percentage of low gradient female patients (mean gradient $<40 \mathrm{mmHg}$ ) was lower and had a trend toward significance $(1.6 \%$ in women vs $5.3 \%$ in men, $\mathrm{p}=0.078$ ). Similarly, aortic valve area was significantly smaller in women $(0.71 \pm 0.18$ vs $0.79 \pm$ $\left.0.19 \mathrm{~cm}^{2}, \mathrm{p}<0.001\right)$. Surgical measured lactate peak serum levels and bypass time were significantly increased in women when compared to men (mean \pm SD $3.0 \pm 0.9$ vs $2.5 \pm 1.0 \mathrm{mmol} / \mathrm{L}, \mathrm{p}<0.001$ and $91.3 \pm 27.6$ vs $98.4 \pm$ $28.7 \mathrm{~min}, \mathrm{p}=0.019$ ). Aortic cross-clamp time presented a similar trend to the time of bypass, with $65.6 \pm 19.1$ min in women and $71.3 \pm 20.6 \mathrm{~min}$ in $\operatorname{men}(\mathrm{p}=0.008)$.

\section{Hospital outcomes}

In-hospital mortality occurred in $2.6 \%$ of women and $1.1 \%$ of men $(\mathrm{p}=0.450)$. Stroke and myocardial infarction did not differ among genders, representing $1.1 \%$ vs $2.2 \%$ and $1.1 \%$ vs $0.5 \%$ of cases, respectively $(\mathrm{p}=0.443$ and $\mathrm{p}=1.000$ ). Conduction disturbances such as atrioventricular block occurred in $7.4 \%$ of women and $5.5 \%$ of men ( $p=0.446)$, with the need for pacemaker in $3.2 \%$ and $2.2 \%$ of cases, respectively $(\mathrm{p}=0.751)$. Cardiac 
arrest was documented in four female patients $(2.1 \%$, $\mathrm{p}=0.123)$. Hemodynamic instability during and after surgery, assessed by the need for inotrope administration, had a high prevalence, and was similar between genders ( $47.6 \%$ vs $48.9 \%, p=0.803)$. Documented infection was similar between genders and occurred in 5.3\% of women and $4.9 \%$ of men $(\mathrm{p}=0.590)$ and prolonged LOS had a prevalence of $23.9 \%$ and $20.3 \%$ in women and men, respectively $(\mathrm{p}=0.414)$. At discharge, amiodarone medicated patients represented $12.3 \%$ of women and $13.2 \%$ of men $(\mathrm{p}=0.805)$ and warfarin was prescribed in $52.6 \%$ of women and $72.5 \%$ of men $(\mathrm{p}<0.001)$.

Impact of POAF in hospital outcomes by gender

POAF had an overall occurrence of $41.2 \%$, with $50 \%$ of cases occurring until the 2nd postoperative daymedian (IQR) of 2 (1) - overall and between genders. POAF did not differ between women and men, presenting an occurrence of $45.0 \%$ vs $39.2 \%(p=0.263)$, respectively. The arrhythmia was either self-limited (34\%) or pharmacologically treated with amiodarone $(57.1 \%)$ or electric cardioversion or both (9\%). There were no differences between genders regarding POAF management, being self-limited in $34.1 \%$ of women vs $33.8 \%$ of men; pharmacologically treated in $55.3 \%$ vs $59.2 \%$ and treated with electrical cardioversion or both in $10.6 \%$ vs $7 \%$ $(\mathrm{p}=0.725)$. Prolonged LOS was significantly different between POSR and POAF patients in both genders$18.2 \%$ vs $31.7 \%(p=0.035)$ for women and $11.8 \%$ vs $35.4 \%(\mathrm{p}<0.001)$ for men. However, infection remained non-significant for each gender and between POSR and POAF (6.8\% vs $3.7 \%, \mathrm{p}=0.516$, in women; $3.6 \%$ vs $7.1 \%, \mathrm{p}=0.423$ in men). As with the case of infection, atrioventricular block remained similar between genders and rhythm group $-5.8 \%$ vs $9.8 \%$ in women, $\mathrm{p}=0.315$ and $5.5 \%$ vs $5.7 \%$ in men, $p=1.000$. Although warfarin was prescribed more frequently in men (see above), in POAF patients, there were no documented differences between genders-warfarin prescribed in $53.4 \%$ of women vs $57.6 \%$ of men $(\mathrm{p}=0.629)$ and amiodarone in $26.0 \%$ vs $32.2 \%(\mathrm{p}=0.436)$. On the other hand, warfarin prescription was significantly higher in POSR men $(51.5 \%$ vs $81.0 \%, \mathrm{p}<0.001)$, with no differences in amiodarone prescription $(2.1 \%$ vs $2.9 \%, \mathrm{p}=0.716)$.

\section{POAF-related factors by gender}

\section{Univariate analysis}

Concerning POAF gender-related factors, patients who developed POAF were generally older in both groups: in women, the mean age was $75 \pm 7.5$ in those who developed POAF and $71 \pm 11.2$ in women who remained in SR $(\mathrm{p}=0.015)$; in men, POAF had a mean age of $72.3 \pm 9.0$ vs $66.2 \pm 10.6$ ( $p<0.001)$. Moreover, coronary artery disease presented as a risk factor for POAF in both groups: $13(16.9 \%)$ vs $3(3.1 \%), p=0.003$, in women; $16(23.5 \%)$ vs 10 (9.5\%), $\mathrm{p}=0.012$, in men.

However, mean aortic gradient was a protective factor for POAF only in women $(51.8 \pm 13.0$ vs $56.1 \pm 15.1$, $\mathrm{p}=0.041)$.

The presence of tricuspid valve disease was associated with increased risk of POAF only in male patients (20 (38.5\%) vs 17 (21.0\%), p = 0.028). Similarly, chronic lung disease was associated with POAF exclusively in men23 POAF patients (33.8\%) vs 17(17.2\%), $\mathrm{p}=0.013$.

Medication did not influence the outcome in either gender. Results for POAF-related factors in men and women are shown in Table 2. Corresponding univariate logistic regression analysis and odds ratios (OR) are depicted in Table 3.

\section{Multivariate analysis}

In women, we identified as independent predictors of POAF advanced age (OR: 1.05; 95\% confidence interval [95\% CI]: 1.01-1.20, $\mathrm{p}=0.02$ ) and mean aortic gradient (OR: 0.964; 95\% CI: 0.937-0.992, p = 0.01). Bypass time showed a tendency toward significance in women (OR: 1.012; 95\% CI: 0.998-1.027, $\mathrm{p}=0.09$ ).

In men, advanced age $(1.071 ;[1.024-1.120], \mathrm{p}=0.003)$ and peak postoperative lactate levels (1.746 [1.034-2.949], $\mathrm{p}=0.037)$ were independently associated with POAF.

AUC $[95 \% \mathrm{CI}]$ of the ROC curves in women and men for the multivariate logistic regression model were, respectively, 0.69 [0.60-0.78] and 0.77 [0.68-0.86] (Fig. 1). Results referring to the previous model in both genders are shown in Table 3.

\section{Mortality analysis}

Median follow-up time for the whole cohort was 38 months, with men and women presenting 37 and 39 months of follow-up, respectively. KM curves for both genders were similar and the Log Rank test was nonsignificant $(\mathrm{p}=0.736)$, therefore not suggesting any difference in long-term mortality between genders (Fig. 2). At 12 months, female patients had a cumulative survival of $94.8 \%$, while for men was $96.8 \%$. At 48 months of follow-up, both gender groups showed a cumulative survival of 93\%. (Fig. 2) Cox regression suggested a reduced ejection fraction as a mortality predictor only in 
Table 2 Univariate analysis

\begin{tabular}{|c|c|c|c|c|c|c|}
\hline & \multicolumn{3}{|c|}{ Female } & \multicolumn{3}{|c|}{ Male } \\
\hline & POSR & POAF & $\mathrm{p}$ value & POSR & POAF & $\mathrm{p}$ value \\
\hline Age (years, mean [SD]) & $71.2(11.1)$ & $74.7(7.5)$ & 0.015 & $66.2(10.6)$ & $72.3(9.0)$ & $<0.001$ \\
\hline Angina (n [\%]) & $27(26)$ & $22(25.9)$ & 0.99 & $36(69.2)$ & $16(30.8)$ & 0.139 \\
\hline Syncope (n [\%]) & $17(16.3)$ & $7(8.3)$ & 0.102 & $18(16.4)$ & $8(11.3)$ & 0.34 \\
\hline NYHA > I (n [\%]) & $52(50)$ & $48(56.5)$ & 0.375 & $55(50)$ & $34(47.9)$ & 0.781 \\
\hline Smoking (n [\%]) & $3(2.9)$ & $4(4.7)$ & 0.703 & $35(31.8)$ & $27(38.0)$ & 0.39 \\
\hline Diabetes (n [\%]) & $40(38.5)$ & $29(34.1)$ & 0.537 & $33(30)$ & $22(31)$ & 0.888 \\
\hline Hypertension (n [\%]) & $79(76)$ & $60(70.6)$ & 0.405 & $79(71.8)$ & $53(74.6)$ & 0.676 \\
\hline Dyslipidemia (n [\%]) & $75(72.1)$ & $58(68.2)$ & 0.561 & $79(71.8)$ & $43(60.6)$ & 0.115 \\
\hline Pulmonary hypertension (n [\%]) & $34(73.9)$ & $28(75.7)$ & 0.854 & $19(79.2)$ & $18(66.7)$ & 0.318 \\
\hline Chronic lung disease (n [\%]) & $13(13.4)$ & $15(20.5)$ & 0.214 & $17(17.2)$ & $23(33.8)$ & 0.013 \\
\hline Coronary artery disease (n [\%]) & $3(3.1)$ & $13(16.9)$ & 0.003 & $10(9.5)$ & $16(23.5)$ & 0.012 \\
\hline Cerebrovascular disease (n [\%]) & $14(13.6)$ & $11(13.1)$ & 0.921 & $7(6.4)$ & $9(12.7)$ & 0.144 \\
\hline Neoplasia (n [\%]) & $7(6.7)$ & $10(11.9)$ & 0.219 & $4(3.6)$ & $7(9.9)$ & 0.113 \\
\hline Statins (n $[\%])$ & $64(71.9)$ & $57(71.3)$ & 0.924 & $62(68.1)$ & $44(68.8)$ & 0.935 \\
\hline Beta-blockers (n [\%]) & $31(34.8)$ & $30(37.5)$ & 0.718 & $27(29.7)$ & $23(35.9)$ & 0.411 \\
\hline ACEI/ARB (n [\%]) & $65(73)$ & $56(70)$ & 0.662 & $58(63.7)$ & $43(67.2)$ & 0.657 \\
\hline Diuretics (n [\%]) & $57(64.0)$ & $52(65.0)$ & 0.897 & $49(53.8)$ & $38(59.4)$ & 0.495 \\
\hline \multicolumn{7}{|l|}{ Ejection fraction } \\
\hline Preserved $(\mathrm{n}[\%])$ & $86(89.6)$ & $68(88.3)$ & 0.779 & $85(88.5)$ & $53(85.5)$ & 0.852 \\
\hline Mildly reduced (n [\%]) & $3(3.1)$ & $4(5.2)$ & & $6(6.3)$ & $5(8.1)$ & \\
\hline Reduced (n [\%]) & $7(7.3)$ & $5(6.5)$ & & $5(5.2)$ & $4(6.5)$ & \\
\hline $\begin{array}{l}\text { Indexed left atrium diameter } \\
(\mathrm{mm} / \mathrm{BMI}, \text { mean }[\mathrm{SD}])\end{array}$ & $707.2(102.9)$ & $731.9(85.7)$ & 0.107 & $671.5(76.1)$ & $694.1(97.0)$ & 0.15 \\
\hline $\begin{array}{l}\text { Indexed left ventricle diameter } \\
(\mathrm{mm} / \mathrm{BMI}, \text { mean }[\mathrm{SD}])\end{array}$ & $814.6(157.0)$ & $822.2(160.4)$ & 0.762 & $\begin{array}{l}798.5 \\
(147.1)\end{array}$ & $792.5(110.8)$ & 0.799 \\
\hline $\begin{array}{l}\text { Indexed interventricular septum } \\
\text { Thickness (mm/BMI, mean [SD]) }\end{array}$ & $225.1(44.4)$ & $225.7(39.6)$ & 0.926 & $203.0(30.0)$ & $213.3(34.6)$ & 0.061 \\
\hline PSAP $(\mathrm{mmHg}$, mean [SD]) & $36.1(10.3)$ & $38.2(12.4)$ & 0.384 & $36.3(8.0)$ & $35.4(9.4)$ & 0.723 \\
\hline $\begin{array}{l}\text { Maximum aortic gradient }(\mathrm{mmHg} \\
\text { mean }[\mathrm{SD}])\end{array}$ & $86.0(20.6)$ & $85.0(19.0)$ & 0.763 & $81.3(19.2)$ & $78.1(16.4)$ & 0.285 \\
\hline Mean aortic gradient (mmHg, mean [SD]) & $56.1(15.1)$ & $51.8(13.0)$ & 0.041 & $51.1(12.4)$ & $49(12.6)$ & 0.301 \\
\hline Aortic valve area $(\mathrm{mmHg}$, mean $[\mathrm{SD}])$ & $0.7(0.2)$ & $0.7(0.2)$ & 0.934 & $0.8(0.2)$ & $0.8(0.2)$ & 0.235 \\
\hline Mitral valve (n [\%]) & $43(48.3)$ & $42(53.2)$ & 0.53 & $37(40.2)$ & $36(55.4)$ & 0.061 \\
\hline Tricuspid valve (n [\%]) & $23(29.5)$ & $22(34.4)$ & 0.533 & $17(21.0)$ & $20(38.5)$ & 0.028 \\
\hline $\begin{array}{l}\text { Surgery peak lactate }(\mathrm{mmol} / \mathrm{L} \text {, } \\
\text { mean }[\mathrm{SD}])\end{array}$ & $2.9(0.8)$ & $3.0(1.0)$ & 0.266 & $2.3(0.6)$ & $2.8(1.3)$ & 0.001 \\
\hline Bypass time (min, mean $[\mathrm{SD}]$ ) & $87.9(23.7)$ & $94.7(31.5)$ & 0.118 & $96.0(27.9)$ & $102.1(29.9)$ & 0.188 \\
\hline Aortic cross-clamp time (min, mean [SD]) & $63.9(15.9)$ & $67.8(22.5)$ & 0.193 & $69.6(20.7)$ & $74(20.4)$ & 0.177 \\
\hline
\end{tabular}

ACEI/ARB: angiotensin converting enzyme inhibitor/angiotensin receptor blocker; NYHA: New York Heart Association Functional Classification; PSAP: pulmonary systolic arterial pressure

women (hazard ratio [HR] 3.645 [1.017-13.070], $\mathrm{p}=$ 0.047 in women vs 1.400 [0.182-10.768], $\mathrm{p}=0.747$ in men), although NYHA functional class was similar between genders and non-significant (0.968 [0.3512.671], $\mathrm{p}=0.950$ in women vs 1.075 [0.377-3.066], $\mathrm{p}=$ 0.892 in men). Aortic valve-related parameters did not associate with increased mortality in any of gender groups-mean aortic gradient had a HR of 1.003 [0.9671.039], $\mathrm{p}=0.892$ in women and 0.969 [0.927-1.014], $\mathrm{p}=0.177$ in men; maximum aortic gradient in women presented a HR of 1.002 [0.976-1.028], $\mathrm{p}=0.906$ and
0.980 [0.951-1.009] $\mathrm{p}=0.168$ in men. Chronic lung disease showed a trend toward significance only in female patients (HR 2.761 [0.925-8.240], $\mathrm{p}=0.069$ vs 1.852 [0.620-5.533], $\mathrm{p}=0.269)$. Diabetes was not associated with increased mortality in either gender groups: 1.521 [0.551-4.194], $\mathrm{p}=0.418$ in female patients vs 0.615 [0.171-2.204], $\mathrm{p}=0.455$ in male patients.

\section{Impact of POAF on mortality by gender \\ Concerning KM curves between POSR and POAF patients, women had no differences when comparing}


Table 3 Logistic regression

\begin{tabular}{|c|c|c|c|c|}
\hline & \multicolumn{2}{|c|}{ Female } & \multicolumn{2}{|c|}{ Male } \\
\hline & Univariate & Multivariate & Univariate & Multivariate \\
\hline Age & $1.041[1.007-1.076] \mathrm{p}=0.017$ & $1.053[1.009-1.099] \mathrm{p}=0.017$ & $1.069[1.032-1.108] \mathrm{p}<0.001$ & $1.071[1.024-1.120] \mathrm{p}=0.003$ \\
\hline Angina & $0.996[0.518-1.915] \mathrm{p}=0.990$ & - & $0.598[0.302-1.186] \mathrm{p}=0.141$ & - \\
\hline Syncope & $0.495[0.183-1.182] \mathrm{p}=0.108$ & - & $0.649[0.266-1.584] \mathrm{p}=0.342$ & - \\
\hline NYHA > I & $1.297[0.729-2.307] \mathrm{p}=0.376$ & - & $0.919[0.506-1.669] \mathrm{p}=0.781$ & - \\
\hline Smoking & $1.663[0.362-7.641] \mathrm{p}=0.514$ & - & $1.315[0.704-2.456] \mathrm{p}=0.391$ & - \\
\hline Diabetes & $0.829[0.456-1.506] p=0.537$ & - & $1.048[0.548-2.002] \mathrm{p}=0.888$ & - \\
\hline Hypertension & $0.759[0.397-1.452] \mathrm{p}=0.405$ & - & $1.155[0.587-2.278] \mathrm{p}=0.676$ & - \\
\hline Dyslipidemia & $0.831[0.444-1.554] \mathrm{p}=0.561$ & - & $0.603[0.320-1.133] \mathrm{p}=0.116$ & - \\
\hline Pulmonary hypertension & $1.098[0.405-2.980] \mathrm{p}=0.854$ & - & $0.526[0.148-1.873] \mathrm{p}=0.322$ & - \\
\hline Chronic lung disease & $1.671[0.740-3.774] \mathrm{p}=0.217$ & $1.690[0.633-4.509] \mathrm{p}=0.295$ & $2.465[1.194-5.089] p=0.015$ & $2.065[0.842-5.063] \mathrm{p}=0.113$ \\
\hline Coronary artery disease & $6.432[1.762-23.479] p=0.005$ & - & $2.923[1.238-6.903] p=0.014$ & - \\
\hline Cerebrovascular disease & $0.958[0.410-2.237] \mathrm{p}=0.921$ & - & $2.136[0.757-6.023] \mathrm{p}=0.151$ & - \\
\hline Neoplasia & $1.873[0.681-5.152] \mathrm{p}=0.224$ & - & $2.898[0.816-10.290] \mathrm{p}=0.100$ & - \\
\hline Statins & $0.968[0.496-1.891] \mathrm{p}=0.924$ & - & $1.029[0.517-2.048] \mathrm{p}=0.935$ & - \\
\hline Beta-blockers & $1.123[0.599-2.105] \mathrm{p}=0.718$ & - & $1.330[0.673-2.626] \mathrm{p}=0.412$ & - \\
\hline ACEI/ARB & $0.862[0.441-1.682] \mathrm{p}=0.662$ & - & $1.165[0.593-2.287] \mathrm{p}=0.657$ & - \\
\hline Diuretics & $1.043[0.555-1.960] \mathrm{p}=0.897$ & - & $1.253[0.656-2.393] \mathrm{p}=0.495$ & - \\
\hline \multicolumn{5}{|l|}{ Ejection fraction } \\
\hline Mildly reduced & $1.686[0.365-7.790] p=0.503$ & $0.863[0.148-5.021] \mathrm{p}=0.869$ & $1.336[0.389-4.597] \mathrm{p}=0.645$ & $0.759[0.174-3.319] \mathrm{p}=0.714$ \\
\hline Reduced & $0.903[0.275-2.972] \mathrm{p}=0.867$ & $0.969[0.214-4.379] \mathrm{p}=0.967$ & $1.283[0.330-4.993] \mathrm{p}=0.719$ & $0.855[0.166-4.403] \mathrm{p}=0.852$ \\
\hline Indexed left atrium diameter & $1.003[0.999-1.006] \mathrm{p}=0.109$ & - & $1.003[0.999-1.007] \mathrm{p}=0.126$ & - \\
\hline Indexed left ventricle diameter & $1.000[0.998-1.002] \mathrm{p}=0.760$ & - & $1.000[0.997-1.002] \mathrm{p}=0.797$ & - \\
\hline $\begin{array}{l}\text { Indexed interventricular septum } \\
\text { thickness }\end{array}$ & $1.000[0.993-1.008] \mathrm{p}=0.926$ & - & $1.011[0.999-1.022] \mathrm{p}=0.064$ & - \\
\hline PSAP & $1.018[0.979-1.058] \mathrm{p}=0.382$ & - & $0.988[0.927-1.053] \mathrm{p}=0.717$ & - \\
\hline Maximum aortic gradient & $0.998[0.982-1.013] \mathrm{p}=0.761$ & - & $0.990[0.972-1.008] \mathrm{p}=0.284$ & - \\
\hline Mean aortic gradient & $0.978[0.957-1.000] p=0.046$ & $0.964[0.937-0.992] p=0.012$ & $0.987[0.962-1.012] \mathrm{p}=0.300$ & $0.998[0.967-1.031] \mathrm{p}=0.915$ \\
\hline Aortic valve area & $1.075[0.197-5.847] \mathrm{p}=0.934$ & - & $0.350[0.058-2.119] \mathrm{p}=0.253$ & - \\
\hline Mitral valve & $1.214[0.662-2.228] \mathrm{p}=0.530$ & - & $1.845[0.971-3.508] \mathrm{p}=0.062$ & - \\
\hline Tricuspid valve & $1.253[0.616-2.546] \mathrm{p}=0.534$ & - & $2.353[1.086-5.099] p=0.030$ & - \\
\hline Surgery peak lactate & $1.211[0.863-1.700] \mathrm{p}=0.269$ & $0.908[0.572-1.442] \mathrm{p}=0.684$ & $2.032[1.282-3.219] p=0.003$ & $1.746[1.034-2.949] p=0.037$ \\
\hline Bypass time & $1.009[0.998-1.021] \mathrm{p}=0.115$ & $1.012[0.998-1.027] \mathrm{p}=0.086$ & $1.007[0.996-1.019] \mathrm{p}=0.189$ & $1.009[0.995-1.024] \mathrm{p}=0.205$ \\
\hline Aortic cross-clamp time & $1.011[0.995-1.027] \mathrm{p}=0.183$ & - & $1.011[0.995-1.026] \mathrm{p}=0.178$ & - \\
\hline
\end{tabular}

Results are presented as odds ratio and $95 \%$ confidence interval - OR [95\% CI].

ACEI/ARB: Angiotensin Converting Enzyme Inhibitor/ Angiotensin Receptor Blocker; NYHA: New York Heart Association Functional Classification; PSAP: pulmonary systolic arterial pressure 


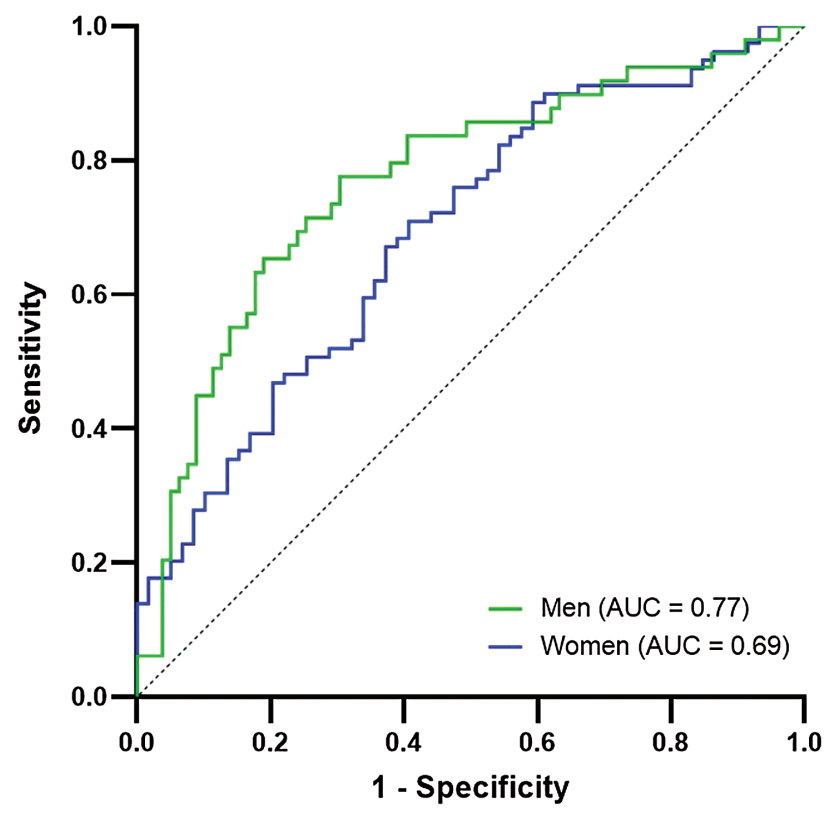

Fig. 1 Area under the ROC curve for the multivariate logistic regression model in men and women

both groups, with a slight superposition between curves (non-significant Breslow test, $\mathrm{p}=0.749$ ). (Fig. 2) At 12 months of follow-up, women who remained in sinus rhythm during the postoperative period had a $97.1 \%$ survival probability, whereas women with POAF presented $95.3 \%$ cumulative survival. At 24 months, women presented a survival probability of $94.2 \%$ and $94.1 \%$, respectively. At 36 months, there was a slight inversion of the KM curves, with POSR women showing a cumulative survival of $94.2 \%$ and POAF women $92.7 \%$ (Fig. 2).

Men, however, had a significant difference between POSR and POAF groups (Log Rank test, $\mathrm{p}=0.024$ ), showing a divergence in the KM curves as early as the first year of follow-up $(99.1 \%$ vs $94.4 \%$ of cumulative survival) (Fig. 2). At 24 months, POSR and POAF male patients presented $97.3 \%$ and $90.1 \%$ probability of survival and at 36 months, survival shifted to $95.8 \%$ and $88.7 \%$, respectively. At 48 months, men with POAF had a cumulative survival of $86.4 \%$, while men in the POSR group maintained the $95.8 \%$ survival probability (Fig. 2) Thus, POAF predicted mortality only in men, with a HR (95\% CI) of 3.551 [1.093-11.532], $\mathrm{p}=0.035$.

\section{Discussion}

In this study, at surgery, women presented more severe aortic valve disease than men, including worsened ventricular re-modeling, with an increased indexed interventricular septum thickness and left atrium diameter. Coronary artery disease, even though non-surgical, and advanced age were predictors of POAF for both genders. The latter emerged as an independent predictor in the multivariate analysis. The remaining risk factors for POAF were gender-specific, with chronic lung disease showing an association with POAF in men, although non-significant in the multivariate analysis. Other valvular disease, although mild, was increased only in male POAF patients. Peak postoperative lactate was an independent predictor of POAF exclusively in men, while higher mean aortic gradient represented an independent protective factor in women. The multivariate model presented significant differences in performance for predicting disease according to gender - a classical prediction model based on clinical, echocardiographic and surgical parameters appears to perform well in men, although lacking efficacy in female patients. Mortality does not differ between genders, either in-hospital or long term. Although POAF occurs similarly in men and women, only in men POAF occurrence predicts long-term mortality. Of the tested variables as potential risk factors for mortality, a reduced ejection fraction associated with an adverse outcome only in women.

In this cohort, POAF had an overall occurrence of $41.2 \%$, with $50 \%$ of cases occurring until the 2 nd postoperative day, which agrees with previous studies, although the arrhythmia varies with patient characteristics, definition of the arrhythmia and methods of heart rhythm monitoring. ${ }^{10)}$ Accordingly, reported POAF peak occurrence is between the second and fourth days post-surgery, with most cases appearing in the first 5 days and only a few after the first week. ${ }^{2,11}$

There is conflicting evidence to whether women are more prone to POAF after CABG than men. Alam et al ${ }^{12)}$ found women have less risk of developing POAF, although it has been reported no difference in risk or increased risk. ${ }^{710)}$ In this study of isolated aortic valve patients, it was observed no difference in POAF occurrence between men and women.

Several clinical and echocardiographic POAF predictors have been identified, such as age, obesity, pulmonary and arterial hypertension, mitral valve disease, left atrium dilation, left atrium volume index, atrial natriuretic peptide (ANP), and subclinical hypothyroidism, with age being the most reproducible risk factor among studies, as confirmed in this study. ${ }^{2}$ There is little evidence on predictors according to gender, and this cohort suggests some potential differential risk factors for POAF in patients submitted to isolated AVR surgery. This study underlines the importance of stratifying patients taking gender into consideration.

Patients who develop AF in the postoperative period are at greater risk of thromboembolic events, infections, 

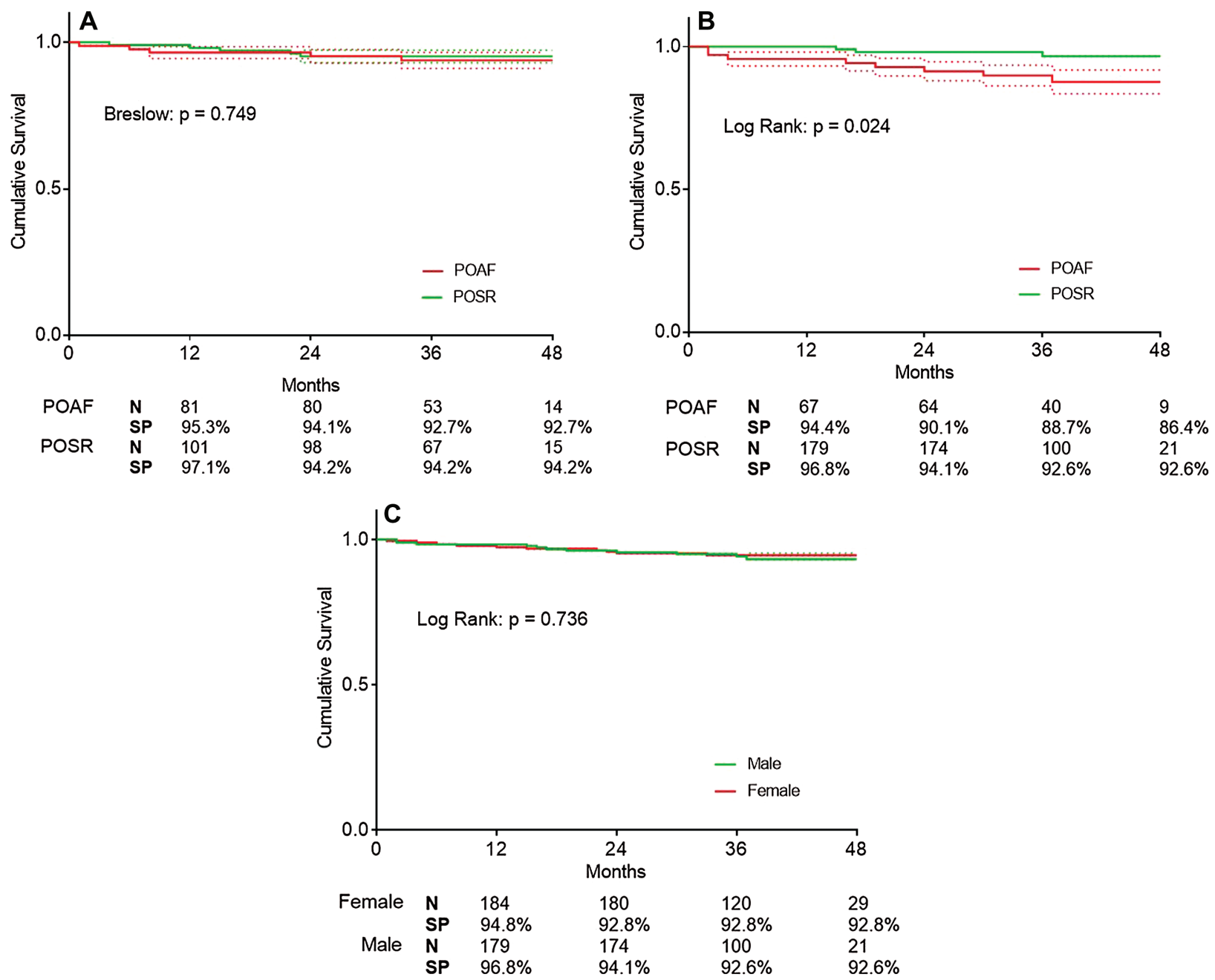

Fig. 2 KM curves and respective survival probabilities between POSR and POAF patients for women (A) and men (B). (C) KM curves between women and men. KM: Kaplan-Meier; N: number of patients at follow-up; POAF: postoperative atrial fibrillation; POSR: postoperative sinus rhythm; SP: survival probability

including pneumonia, respiratory failure, renal failure, intensive care unit readmission, prolonged LOS, increased overall costs, and 30-day mortality.,13,14) In this cohort of patients, prolonged LOS was in fact different between POSR and POAF patients. On the other hand, there were no differences concerning in-hospital outcomes between these groups in each gender, although events were sparse and thus difficult to identify differences objectively.

Numerous studies in CABG surgery have reported higher hospital mortality in female patients than in their male counterparts, ${ }^{12,15)}$ although mid- and long-term mortality appears to be similar in both gender groups. ${ }^{8}{ }^{86}$ There is some evidence to suggest that between 5 and 6 years after CABG surgery, the results are the same or might be better for female patients, as suggested by the work of Abramov et al. with the increase in female late survival after
CABG. ${ }^{17)}$ Ahmed et al. recruited 1114 women and 3628 men submitted to CABG surgery and evaluated morbidity and mortality for a follow-up of 7.9 years. The study concluded women had increased long-term cardiac mortality even though similar all-cause mortality. ${ }^{18)}$ Similarly to CABG surgery, women have a higher preoperative risk than men in combined valvular and CABG surgery, ${ }^{19)}$ representing an independent risk factor for post-surgery morbidity and mortality. ${ }^{20)}$ Likewise, in AVR surgery, female gender predicts increased in-hospital and 30-day all-cause mortality. ${ }^{21-23)}$ Concerning long-term mortality, Elhmidi et al. reported no influence of gender in late mortality in a cohort of 2197 patients submitted to isolated AVR surgery. Several studies agree with this finding, suggesting gender does not influence long-term outcomes in AVR. ${ }^{19,24)}$ In this cohort of patients, although no difference in postoperative mortality was observed between genders, female patients 
did show an increased preoperative risk, with worse disease, and longer surgical timings (bypass time) as well as worse response to surgery (peak lactate). Concerning overall long-term mortality, men and women had similar survival probabilities at a maximum follow-up of 52 months, which concurs with what is observed in the literature.

Furthermore, several studies have implicated POAF in short- and long-term mortality, which suggests the need to monitor this group of patients closely. ${ }^{14,25)}$ In this cohort, POAF had a trend toward significance as a risk factor for long-term mortality (data not shown). Furthermore, POAF after CABG has been reported as a predictor of long-term mortality in female patients but not in males. ${ }^{26)}$ The present study suggests POAF as a predictor of long-term mortality in men but not in women, in patients submitted to isolated AVR surgery, which does not agree with the available literature in CABG. This finding does not appear to be related to baseline characteristics as both men and women with POAF are older and have higher comorbidity rates; moreover, other risk factors tested by cox regression in men did not influence mortality. It has been suggested men are more prone to develop AF than women, although the basis for these differences remain unclear. Men have increased expression of relevant repolarizing ion channel subunits, which might decrease repolarization time and thus abbreviate atrial refractoriness and promote re-entry. ${ }^{27)}$ In this cohort, only POAF in men predicts permanent AF during the first year; in women, POAF does not predict AF (data not shown). This suggests POAF in men represents either electrical and/or structural re-modeling as an arrhythmia-developing substrate, although indexed left atrium diameter does not predict POAF in either gender in this cohort. Conversely, women could develop a more benign POAF with transitory inflammation as the main risk factor for the arrhythmia, thus not predicting established AF at follow-up. Inflammation is a recognized pathway for POAF, with C-reactive protein, IL-6 and IL-2 being implicated in the development of the arrhythmia; treatment with anti-inflammatory agents has been reported to decrease POAF occurrence. ${ }^{28)}$ Thus, POAF could predict mortality in men because it predicts established AF only in this gender. Men could have to be more aggressively treated to prevent permanent AF and related morbidity and mortality, although more studies are necessary to confirm this hypothesis and explore other mechanisms of gender-related differences in AF pathophysiology.

$\mathrm{POAF}$ is a known risk factor for permanent $\mathrm{AF}$, as well as morbidity and mortality, including thromboembolic events. ${ }^{14,25)}$ There are several studies on the prevention ( $\beta$-blockers, colchicine, etc.) and early treatment of POAF although not according to gender. ${ }^{1,29}$ This study suggests men might benefit more from the prevention of the arrhythmia than women, although only all-cause mortality differed between men and women who presented POAF. Other outcomes, as increased hospital stay and immediate postoperative morbidity, were similar between genders. In addition, these results could potentially translate to transcatheter aortic valve implantation (TAVI), as new-onset post-procedure AF occurs in up to $32 \%$ of cases and, although some studies do not report differences between men and women, disparities in long-term all-cause mortality between genders are still debatable. ${ }^{30}$

This cohort is retrospective, which is a limitation of this study. POAF definition is based on written records which could under-detect our main outcome. Still, our prevalence reports are similar to existing literature. Furthermore, larger cohorts are necessary to confirm these results and increase evidence on gender differences in both predictors of POAF and POAF impact on mortality.

\section{Conclusion}

Although larger cohorts are needed to confirm these results, this study underlines the importance of stratifying patients according to gender and finding genderspecific prediction models for POAF. Patients who develop new-onset AF following isolated AVR surgery need to be closely monitored, although mortality appears to be increased only in men.

\section{Acknowledgements}

This study was supported by the Cardiovascular R\&D Center, financed by national funds through FCT - Fundação para a Ciência e Tecnologia, I.P., under the scope of the projects UID/IC/00051/2019 and UIDP/00051/2020.

\section{Disclosure Statement}

The authors declare that there is no conflict of interest.

\section{References}

1) Maaroos M, Pohjantähti-Maaroos $\mathrm{H}$, Halonen J, et al. New onset postoperative atrial fibrillation and early anticoagulation after cardiac surgery. Scand Cardiovasc J 2017; 51: 323-6. 
2) Yilmaz MB, Erbay AR, Balci M, et al. Atrial natriuretic peptide predicts impaired atrial remodeling and occurrence of late postoperative atrial fibrillation after surgery for symptomatic aortic stenosis. Cardiology 2006; 105: 207-12.

3) Villareal RP, Hariharan R, Liu BC, et al. Postoperative atrial fibrillation and mortality after coronary artery bypass surgery. J Am Coll Cardiol 2004; 43: 742-8.

4) Ferrari E, Tozzi P, Hurni M, et al. Primary isolated aortic valve surgery in octogenarians. Eur J Cardiothorac Surg 2010; 38: 128-33.

5) Langanay T, Rouzé S, Tomasi J, et al. Conventional aortic valve replacement in 2005 elderly patients: a 32-year experience. Eur J Cardiothorac Surg 2018; 54: 446-52.

6) López-de-Andrés A, Méndez-Bailón M, Perez-Farinos $\mathrm{N}$, et al. Gender differences in incidence and in-hospital outcomes of surgical aortic valve replacement in Spain, 2001-15. Eur J Public Health 2019; 29: 674-80.

7) Basaran M, Selimoglu O, Ozcan H, et al. Being an elderly woman: is it a risk factor for morbidity after coronary artery bypass surgery? Eur J Cardiothorac Surg 2007; 32: 58-64.

8) Erguneş K, Yilik L, Yetkin U, et al. Early and midterm outcomes in female patients undergoing isolated conventional coronary surgery. J Cardiovasc Thorac Res 2014; 6: 105-10.

9) Frendl G, Sodickson AC, Chung MK, et al. 2014 AATS guidelines for the prevention and management of perioperative atrial fibrillation and flutter for thoracic surgical procedures. J Thorac Cardiovasc Surg 2014; 148: e153-93.

10) Kokkonen L, Järvinen $O$, Majahalme S, et al. Atrial fibrillation in elderly patients after coronary artery bypass grafting; gender differences in outcome. Scand Cardiovasc J 2005; 39: 293-8.

11) Kirchhof P, Benussi S, Kotecha D, et al. 2016 ESC Guidelines for the management of atrial fibrillation developed in collaboration with EACTS. Eur Heart J 2016; 37: 2893-962.

12) Alam M, Lee VV, Elayda MA, et al. Association of gender with morbidity and mortality after isolated coronary artery bypass grafting. A propensity score matched analysis. Int J Cardiol 2013; 167: 180-4.

13) Tran DT, Perry JJ, Dupuis JY, et al. Predicting newonset postoperative atrial fibrillation in cardiac surgery patients. J Cardiothorac Vasc Anesth 2015; 29: 1117-26.

14) Phan K, Ha HSK, Phan S, et al. New-onset atrial fibrillation following coronary bypass surgery predicts longterm mortality: a systematic review and meta-analysis. Eur J Cardiothorac Surg 2015; 48: 817-24.

15) Khan JK, Shahabuddin S, Khan S, et al. Coronary artery bypass grafting in South Asian patients: impact of gender. Ann Med Surg 2016; 9: 33-7.

16) Guru V, Fremes SE, Austin PC, et al. Gender differences in outcomes after hospital discharge from coronary artery bypass grafting. Circulation 2006; 113: 507-16.

17) Abramov D, Tamariz MG, Sever JY, et al. The influence of gender on the outcome of coronary artery bypass surgery. Ann Thorac Surg 2000; 70: 800-5; discussion 806.

18) Ahmed WA, Tully PJ, Psych M, et al. Female sex as an independent predictor of morbidity and survival after isolated coronary artery bypass grafting. Ann Thorac Surg 2011; 92: 59-67.

19) Doenst T, Ivanov J, Borger MA, et al. Sex-specific long-term outcomes after combined valve and coronary artery surgery. Ann Thorac Surg 2006; 81: 1632-6.

20) Ibrahim MF, Paparella D, Ivanov J, et al. Genderrelated differences in morbidity and mortality during combined valve and coronary surgery. J Thorac Cardiovasc Surg 2003; 126: 959-64.

21) Chaker Z, Badhwar V, Alqahtani F, et al. Sex differences in the utilization and outcomes of surgical aortic valve replacement for severe aortic stenosis. J Am Heart Assoc 2017; 6: pii:e006370.

22) Wong SC, Yeo I, Bergman G, et al. The influence of gender on in-hospital clinical outcome following isolated mitral or aortic heart valve surgery. Cardiovasc Revasc Med 2018; 20: 468-74.

23) Elhmidi Y, Piazza N, Mazzitelli D, et al. Sex-related differences in 2197 patients undergoing isolated surgical aortic valve replacement. J Card Surg 2014; 29: 772-8.

24) Hartzell M, Malhotra R, Yared K, et al. Effect of gender on treatment and outcomes in severe aortic stenosis. Am J Cardiol 2011; 107: 1681-6.

25) El-Chami MF, Kilgo P, Thourani V, et al. New-onset atrial fibrillation predicts long-term mortality after coronary artery bypass graft. J Am Coll Cardiol 2010; 55: 1370-6.

26) Lee SH, Lee H, Park JK, et al. Gender difference in the long-term clinical implications of new-onset atrial fibrillation after coronary artery bypass grafting. Yonsei Med J 2017; 58: 1119-27.

27) Gaborit N, Varro A, Le Bouter S, et al. Gender-related differences in ion-channel and transporter subunit expression in non-diseased human hearts. J Mol Cell Cardiol 2010; 49: 639-46.

28) Harada M, Van Wagoner DR, Nattel S. Role of inflammation in atrial fibrillation pathophysiology and management. Circ J 2015; 79: 495-502.

29) Lennerz C, Barman M, Tantawy M, et al. Colchicine for primary prevention of atrial fibrillation after openheart surgery: systematic review and meta-analysis. Int J Cardiol 2017; 249: 127-37.

30) Katz M, Carlos Bacelar Nunes Filho A, Caixeta A, et al. Gender-related differences on short- and long-term outcomes of patients undergoing transcatheter aortic valve implantation. Catheter Cardiovasc Interv 2017; 89: $429-36$. 